Review Article

\title{
Management of Simultaneous Bilateral Femur Fractures in a Tertiary Care Hospital: A Retrospective Review
}

\author{
Syed Zohaib Gulzar Naqvi ${ }^{1, *}$, Raza Askari ${ }^{1}$, Masood Umer $^{2}$ and Umair Ahsraf ${ }^{1}$ \\ ${ }^{\text {I}}$ Department of Orthopedic Surgery, Aga Khan University and Hospital, Karachi, Pakistan. \\ ${ }^{2}$ Department of General Surgery, Section Orthopedics, Aga Khan University and Hospital, Karachi, Pakistan.
}

\begin{abstract}
Introduction: Bilateral long bone fractures are rare and usually are associated with increased risk of complications. These fractures are usually associated with poly traumatic injuries or high impact trauma resulting in shock. Commonest etiology is road traffic accident. Closed diaphyseal fractures are best managed by intramedullary nailing; management becomes difficult if there are open fractures and late arrival. In this study we intend to present our experience of managing these patients.

Materials and Methods: Medical records of all adult patients (age more than 16 years of age) admitted at Aga Khan University and Hospital with bilateral femur fractures +/- other systemic injuries 2006-2014 were reviewed retrospectively. Adult patients with complete medical records were included and patients with missing data were excluded from the study. SPSS version 19 was used for data entering and Statistical analysis.

Results: We retrieved 11 cases of bilateral femur fractures. Mean age of patients was $34.5+/-20.9$, with male predominance constituting 72.7\%. Common mode of injury was fall from height and road traffic accident (RTA) $45.5 \%$ each, with the exception of one gunshot. Mean Injury Severity Score was 26.9+/-7.79. Mean Revised Trauma Score was 7.39 +/-0.62; mean Trauma Injury and Severity Score was 92.4 +/6.6\%. 2 patients had surgical site infections and 1 had non-union. We encountered no mortality. Increase ISS is associated with increased risk of morbidity and length of hospital stay $(\mathrm{p}=0.02)$.
\end{abstract}

Keywords: IM -Intramedullary nailing, ISS- injury severity score, RTS-revise trauma score, LCP- locking compression plate. doi.org/10.21089/njhs.21.0035

\section{INTRODUCTION}

Bilateral femoral fractures have always been considered by trauma surgeons to indicate a more severe injury and are commonly the result of a very high-energy impact with an increased risk of morbidity and mortality [1]. The term "damage control orthopedics" (DCO) was coined for an individualized treatment concept for multiple trauma patients with bone injury. The strategy of the delayed secondarydefinitive internal osteosynthesis after temporary external fixation may reduce "second hit" in patients with severe multiple trauma, hence minimizing the morbidity and mortality. However, the optimal criteria for defining which patients should be managed by the DCO strategy has been not clear yet, and the assessment of systemic damage inflicted by surgery was mainly based on clinical observations by experienced surgeons. In general, surgeons prefer DCO principle in those patients who are unstable or with a high Injury Severity Score (ISS) [2].

*Address correspondence to this author at the Department of Orthopedic Surgery, Aga Khan University and Hospital, Karachi, Pakistan.

Tel: 0346-2757529; E-mail: zohaib.naqvi1@ gmail.com

(C) 2017 NiBD Publications
Controversy exists in the treatment of bilateral femoral fractures in patients with multiple injuries. Previous studies clearly demonstrate that traction should be minimized to avoid the attendant risks of pulmonary complications, infection, and thromboembolic events associated with recumbency [3]. Since this principle was established nearly three decades ago, two strategies have emerged for the treatment of femoral fractures in the setting of multiple traumas: early definitive stabilization and damage control orthopedics (DCO). Early definitive stabilization refers to definitive fixation within approximately 24 hours of injury. Compared with delayed stabilization, early definitive stabilization has been shown to be associated with fewer pulmonary complications, shorter hospital length of stay (LOS), and lower costs of care [4, 5].

These fractures are usually associated with poly traumatic injuries or high impact trauma. In our part of world bilateral long bones fracture secondary to gunshot injuries are also not rare despite of road traffic accidents. It is considered that this increase rate of complications associated with bilateral long bone fracture is the resultant of those poly trauma inju- 
ries rather than two simultaneous fractures itself. We intended to review our data of management of bilateral femur fractures to find out rather bilateral long bone fracture is responsible for increase mortality and morbidity or the associated injuries are the culprit.

\section{OBJECTIVE}

The objective of this study was to review the management and resultant associated mortality with bilateral femur fractures at our institute.

\section{MATERIALS AND METHODS}

Medical records of all adult patients (age more than 16 years of age) admitted at Aga Khan University and Hospital with bilateral femur fractures +/- other systemic injuries 20062014 were reviewed retrospectively. Adult patients with complete medical records were included and patients with missing data were excluded from the study. Patients demographic data was taken into account with mode of injury, vitals, Glasgow Coma Score (GCS) at presentation, Injury severity score (ISS), Revised Trauma score (RTS), associated injuries, mode of fixation, morbidity and mortality were accounted for. SPSS version 19 was used for data entering and Statistical analysis.

\section{RESULTS}

In our retrospective review we retrieved 11 cases of bilateral femur fractures. Mean age of patients was $34.5+/-20.9$, with male predominance constituting $\{n=8(72.7 \%)\}$ (Fig. 1). Common mode of injury was fall from height and road traffic accident (RTA) $45.5 \%$ each, with the exception of 1 gunshot. Majority of the patients $(n=5) 62.5 \%$ were referred from other hospitals. Three patients had systolic B.P between $80-90 \mathrm{~mm}$ of $\mathrm{Hg}$ and 7 patients had pulse more than 100 beats per minute, majority $(n=9)$ had GCS $15 / 15$. Among 22 long bones fracture in all, 5 were open fracture which were managed with external fixator and illizarov (Fig. 2). Four patients had other fractures, and 6 patients had other associated injuries in which 1 had a compromised airway as well. 4 of the patients had significant chest injuries (especially contusions), one patient had abdominal injury (liver laceration) in addition to lung injury and 1 had urethral injuries. Mean Injury Severity Score was 26.9+/-7.79, mean Revised Trauma Score was $7.39+/-0.62$; mean Trauma Injury Severity Score was $92.4+/-6.6 \%$.. 3 patients were admitted in special care unit and 1 in surgical ICU because of chest injury. Mean length of stay at hospital was 14.1 days. Increase length of stay is comparable with increase in ISS $(p=0.02)$ as shown in Table 1. Among 22 femurs, 16 underwent intramedullary interlocking nail fixation, followed by illizarov for 4 femurs, 1 femur fixed with locking femur plate and 1 with conventional AO fixator as shown in (Fig. 3). Non- weight bearing mobilization was started on $1^{\text {st }}$ post-operative day and range of motion exercises were started on $2^{\text {nd }}$ post-operative day. 2 patients had surgical site infections and 1 had non-union who was already suffering from metabolic disease. None of the patient sufferedmortality.

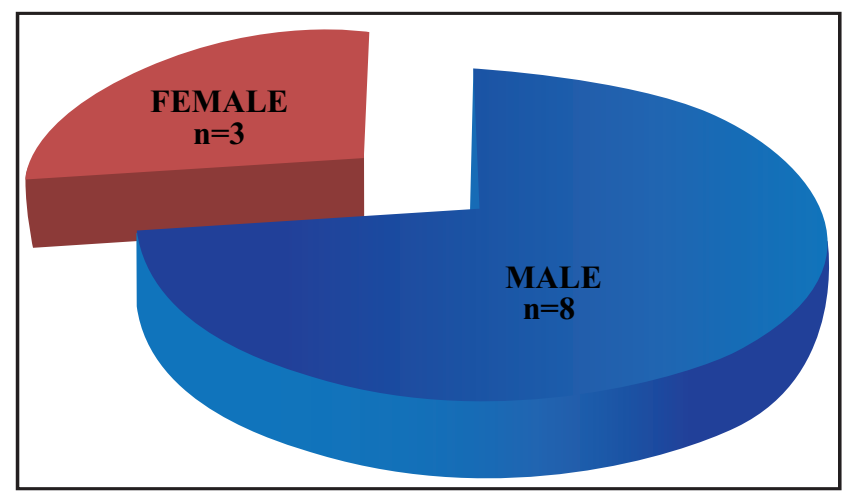

Fig. (1). Showing male predominance in patient presenting with bilateral femur fracture.

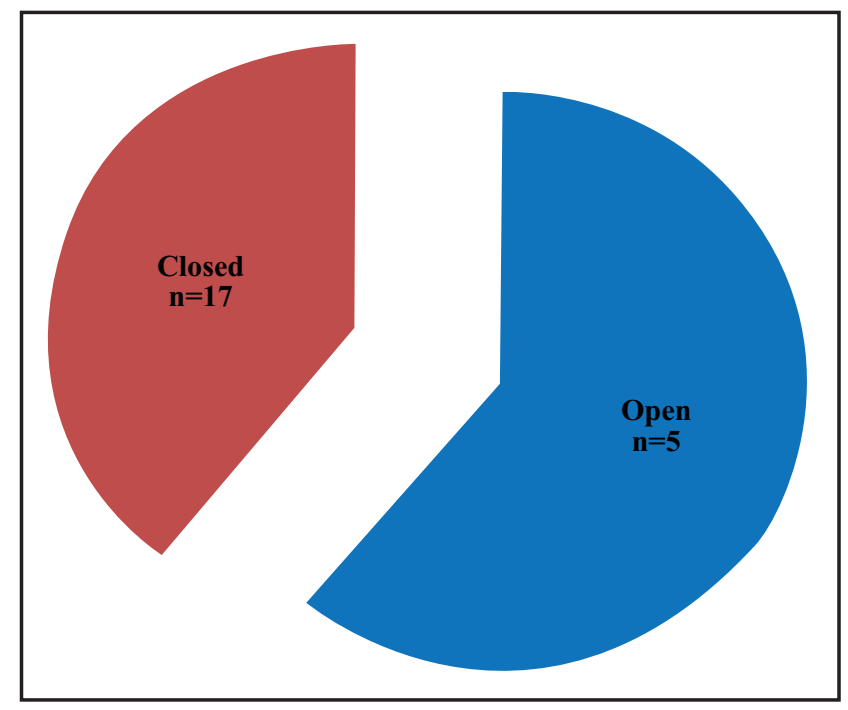

Fig. (2). Showing frequency of open and closed femur fracture in 22 bones (11 patients).

\section{DISCUSSION}

Bilateral femur fractures are uncommon injuries and in our study have an incidence of $3.2 \%$. This is comparable to the incidence rate reported by other authors $[6,7]$. These injuries result from high energy forces such as motor vehicle collisions. Injuries and their complications in bilateral femur fracture patients can be life-threatening and may include hemorrhage, internal organ injury, wound infection, fat embolism, and adult respiratory distress syndrome [8, 9]. These fractures result in major physical impairment due to potential fracture shortening, mal-alignment, or prolonged immobilization of the extremity with casting or traction. Injury severity score has been implicated to quantify the severity of an 
injury, estimate the probability of survival, facilitate prehospital triage, allow accurate comparison of different trauma populations, evaluate trauma care, compare trauma care among hospitals, and organize and improve trauma systems. The spectrum of injury severity score in our study ranged from moderate to severe same as studied by Kopp et al. [10]. Five out of nine patients had various grades of shock while rest were vitally stable as shown in (Fig. 4). Literature and physiological studies on animals have shown that in patients who presented in shock the treatment would better be in staged, one with stabilization initially and then definite procedure. In our study, all patients were initially resuscitated and then went ahead with definite procedures these includes both who presented earlier and late.

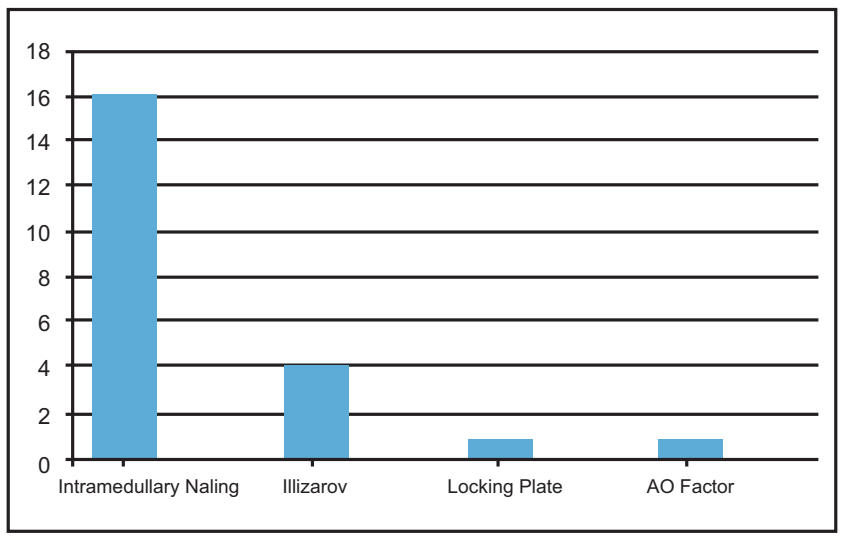

Fig. (3). Showing frequency of mode of fixations of femur fractures.

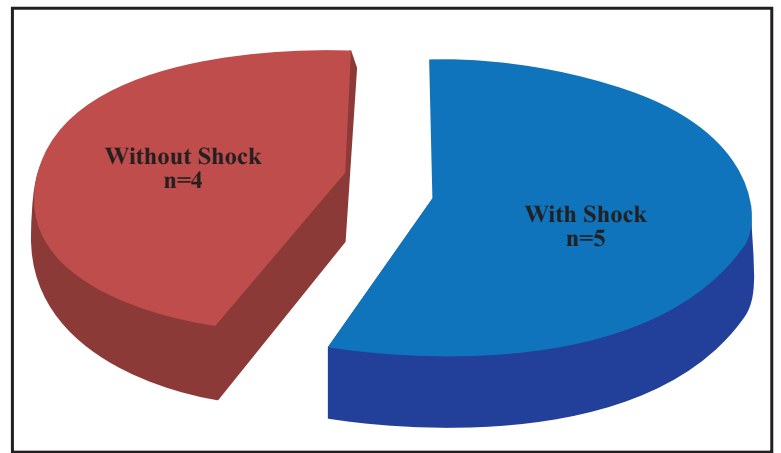

Fig. (4). Showing frequency of patients with and without shock.

In our audit, 5 patients had multiple injuries hence also required multiple surgeries. These were the same patients who also presented to us with shock, these patients underwent adequate resuscitation and close monitoring. Keith et al. showed that bilateral femur fracture itself and associated other systemic injuries are life threatening and are to be managed acutely initially, reinforcing fracture stabilization as soon as patient condition allows [11]. Recently [12] favors early stabilization but further evidence still needs to be looked upon before a definitive opinion can be established.
Simultaneous bilateral femoral shaft fractures mortality has shown to be as high as $16 \%$ in a study by [13], surprisingly we encountered no mortality. The authors believe that due of initial adequate resuscitation and management no mortality was reported, and our patients had minimum morbidity. Furthermore, we are unaware of any data that specifically showed the stabilization of long bone fractures, in particular fractures of the femoral diaphysis, less than 8 hours after injury is more beneficial than such stabilization performed within 24 hours of injury [14]. Early reamed intramedullary nailing being acceptable option for stabilization of the fracture after initial resuscitation [15], and is well tolerated with minimal incidence of complication comparable with our study. But we found that an increase ISS among bilateral femur fracture patients is associated with prolonged hospital stay.

\section{CONCLUSION}

Bilateral femur fractures are fairly uncommon then unilateral fracture. Patient with these injury consider having high intensity impact which hence increase the traumatic stress on the body, therefore good resuscitation is milestone, aiding in better outcome. Increased ISS in bilateral femur fracture patients are comparable with prolonged hospital stay.

Table 1. Mean severity score, mean length of hospital stay and statistical relation between severity scores and length of stay.

\begin{tabular}{|c|c|c|}
\hline Injury Severity Scores & Value & $\begin{array}{c}\text { Statistical Significance } \\
\text { with Length of Stay }\end{array}$ \\
\hline Mean ISS & $26.9+/-7.79$ & Comparable (p=0.02) \\
\hline Mean RTS & $7.39+/-0.62$ & Not comparable \\
\hline Mean TRISS & $92.4+/-6.6 \%$ & Not comparable \\
\hline Mean length of stay & 14.1 days & \\
\hline
\end{tabular}

\section{ACKNOWLEDGEMENT}

Declared none.

\section{CONFLICT OF INTEREST}

Declared none.

\section{REFERENCES}

[1] Lane MK, Nahm NJ, Vallier HA. Morbidity and Mortality of Bilateral Femur Fractures. Orthop. 2015; 38(7): e588-92. doi: 10.3928/01477447-20150701-56.

[2] Tiansheng S, Xiaobin C, Zhi L, Xiaowei W, Guang L, and Liren Z, Is damage control orthopedics essential for the management of bilateral femoral fractures associated or complicated with shock? an animal study, J. Trauma. Inj. Inf. Criti. Care, 2009; 67(6): 14021411 . 
[3] Riska EB, von Bonsdorff H, Hakkinen S, Jaroma H, Kiviluoto O,Paavilainen T. Primary operative fixation of long bone fractures in patients with multiple injuries. J. Trauma., 1977; 17: 111-121.

[4] Bone LB, Johnson KD, Weigelt J, Scheinberg R. Early versus delayed stabilization of femoral fractures. A prospective randomized study. J. Bone Joint Surg. Am., 1989; 71: 336-340.

[5] Behrman SW, Fabian TC, Kudsk KA, Taylor JC. Improved outcome with femur fractures: early vs. delayed fixation. $J$. Trauma., 1990; 30: 792-797.

[6] Carr CR, Wingo CH Fractures of the femoral diaphysis. J. Bone Joint Surg., Am., 1973; 55: 690-700.

[7] Dencker H, Shaft fractures of the femur. A comparative study of the results of various methods of treatment in 1003 cases. Acta Chir Scand, 1965; 130: 173-184.

[8] Behrman SW, Fabian TC, Kudsk KA. Improved outcome with femur fractures: Early vs delayed fixation. J. Trauma., 1990; 30: 792-797.

[9] Bone LB, Johnson KD, Weigelt J, Scheinberg R. Early versus delayed stabilization of femoral fractures. A prospective randomized study. J. Bone Joint Surg. Am., 1989; 71: 336-340.

[10] Kobbe P1, Micansky F, Lichte P, Sellei RM, Pfeifer R, Dombroski D, Lefering R, Pape HC; Trauma Register DGU. Increased morbidity and mortality after bilateral femoral shaft fractures: myth or reality in the era of damage control? Injury. 2013; 44(2): 221-5. doi: 10.1016/j.injury.2012.09.011.

[11] Willett K, Al-Khateeb H, Kotnis R, Bouamra O, and Lecky F, Risk of mortality: the relationship with associated injuries and fracture treatment methods in patients with unilateral or bilateral femoral shaft fractures, J. Trauma., 2010; 69(1): 405-410.

[12] Nahm NJ., John Como J, Wilber JH., and Vallier HA. Early appropriate care: definitive stabilization of femoral fractures within 24 hours of injury is safe in most patients with multiple injuries. J. Trauma. 2011; 71(1): 175-185.

[13] Lichte P, Weber C, Sellei RM, Hildebrand F, Lefering R, Pape HC Kobbe P. Are bilateral tibial shaft fractures associated with an increased risk for adverse outcome?. Injury, Int. J. Care Inj., 2014; 45: 1985-1989.

[14] Robert V. O'Toole, MD, Michael O'Brien, MD, Thomas M. Scalea, MD, Nader Habashi, MD,Andrew N. Pollak, MD, and Clifford H. Turen, MD, Resuscitation before stabilization of femoral fractures limits acute respiratory distress syndrome in patients with multiple traumatic injuries despite low use of damage control orthopedics, J. Trauma., 2009; 67(5): 1013-1021.

[15] Giannoudis PV, Cohen A, Hinsche A, Stratford T, Matthew SJ, Smith R.M. Simultaneous bilateral femoral fractures: systemic complications in 14 cases. Inter. Orthop. (SICOT). 2000; 24: 264267.

(C) 2017 National journal of health sciences.

This is an open-access article. 